\title{
Exploring Sexually Transmitted Infections Testing Practices and Prevalence Among Urban Refugee Adolescent Girls and Young Women in Kampala, Uganda
}

\author{
Dr. C.H. Logie ${ }^{* 1}$, Mr. M. Okumu1, Mr. S. Mwima², Dr. J. Musigunzi², \\ Dr. S. Neema ${ }^{3}$, Mr. I Rungu4 ${ }^{4}$ Mr. E. Kironde ${ }^{5}$
}

1. Factor-Inwentash Faculty of Social Work, University of Toronto; 2. Uganda Ministry of Health; 3. Makerere University; 4. Tomorrow Vijana; 5. Interaid Uganda

Contact: Dr. Carmen Logie, Factor-Inwentash Faculty of Social Work, University of Toronto; Canada. carmen.logie@utoronto.ca

$$
\text { Background }
$$

Uganda hosts over 1 million refugees-most women and girls. Sexually transmitted infections (STI) vulnerabilities among refugee adolescent girls and young women (AGYW) are shaped by social and structural factors, including poverty and limited healthcare access. There are knowledge gaps regarding STI testing practices among urban refugee AGYW in Uganda; studies reported a $20.6 \%$ STI prevalence among general populations of AGYW in Kampala. The study objective was to examine STI testing practices among urban refugee AGYW in Kampala.

\section{Methods}

We conducted a cross-sectional tablet-based survey from January-March 2018 in 5 slum communities (Nsambya, Katwe, Kasanga, Kabalangala, Rubanga) in Kampala, Uganda with refugee girls and women aged 16-24. Participants were recruited using peer-driven sampling, a method known to increase hidden population's participation in research. We conducted bivariate and multivariate logistic regression to examine factors associated with the likelihood of lifetime STI testing.

\section{Results}

In unadjusted analyses (Table 1), STI testing was associated with increased age, being in a dating relationship, food security, condom use self efficacy, access to sexual and reproductive health information, depressive symptoms, and stigma lay attitudes. Those with higher sexual and reproductive health enacted and internalized stigma had lower odds of testing. In adjusted analyses, STI testing was associated with structural (access to sexual and reproductive health information, food security), social (lower enacted stigma, higher lay provider stigma), and intrapersonal (depression) factors.

\section{Conclusions}

Findings reveal high STI prevalence, and suboptimal access to STI testing services, among urban refugee AGYW in Kampala. Innovative, multi-level strategies that tackle stigma and structural drivers are urgently needed to increase access to, and uptake of, STI testing among AGYW to advance sexual and reproductive health.

\section{Participants}

Participants ( $n=333$; mean age: 19.3, SD: 2.56) identified their country of birth as: Democratic Republic of the Congo (45.9\%), Burundi (33.3\%), South Sudan (9.0\%), Rwanda (5.7\%) and others (6.0\%). One-third $(n=108,32.4 \%)$ reported awareness of STI testing availability in their area, and $29.4 \%$ $(\mathrm{n}=98)$ reported lifetime $\mathrm{STI}$ testing. Of participants who had received an STI test, $28.6 \% \quad(n=28)$ reported an STI history (herpes: $n=17$; syphilis: $n=6$, gonorrhea: $n=5$ ) and $18.4 \%$ did not know their results
Table 1: Logistic Regression Analyses of Factors Associated with Likelihood of STI testing among Refugee Adolescent Girls and Young Women in Kampala, Uganda $(n=333)$

\begin{tabular}{|c|c|c|}
\hline \multirow[t]{2}{*}{ Variables } & \multicolumn{2}{|r|}{ STI testing } \\
\hline & $\begin{array}{r}\text { Unadjusted OR (95\% } \\
\mathrm{Cl})\end{array}$ & $\begin{array}{r}\text { Adjusted OR (95\% } \\
\mathrm{Cl})^{*}\end{array}$ \\
\hline Age & $1.20(1.10,1.31)^{\star \star \star}$ & $1.02(0.88,1.18)$ \\
\hline \multicolumn{3}{|l|}{ Dating relationship } \\
\hline No & 1 & 1 \\
\hline Yes & $2.19(1.24,3.86)^{\star \star}$ & $1.47(0.68,3.18)$ \\
\hline \multicolumn{3}{|l|}{ Food insecurity } \\
\hline No & 1 & 1 \\
\hline Yes & $0.35(0.19,0.65)^{\star \star \star}$ & $0.25(0.12,0.55)^{\star \star \star}$ \\
\hline SRH Stigma & $0.94(0.89,0.99)^{*}$ & \\
\hline Enacted stigma & $0.73(0.62,0.85)^{\star \star \star}$ & $0.62(0.47,0.81)^{\star \star \star}$ \\
\hline Internalized stigma & $0.86(0.76,0.97)^{\star}$ & $0.91(0.71,1.16)$ \\
\hline Stigma lay attitudes & $1.05(0.91,1.20)$ & $1.38(1.11,1.72)^{\star \star}$ \\
\hline \multicolumn{3}{|l|}{ Depression } \\
\hline No symptoms & 1 & 1 \\
\hline Moderate symptoms & $2.60(1.11,6.14)^{\star}$ & $3.17(1.11,9.02)^{\star}$ \\
\hline Condom use self-efficacy & $1.04(1.01,1.07)^{\star}$ & $1.03(0.98,1.07)$ \\
\hline \multicolumn{3}{|l|}{ Access to SRH information } \\
\hline $\begin{array}{ll} & \text { No } \\
\end{array}$ & 1 & 1 \\
\hline Yes & $4.8(2.50,9.20)^{\star \star \star}$ & $8.49(3.38,21.32)^{\star \star \star}$ \\
\hline
\end{tabular}

